\title{
COMPARISON OF ESTIMATION ACCURACY OF EKF, UKF AND PF FILTERS
}

\begin{abstract}
Several types of nonlinear filters (EKF - extended Kalman filter, UKF - unscented Kalman filter, PF - particle filter) are widely used for location estimation and their algorithms are described in this paper. In the article filtering accuracy for non-linear form of measurement equation is presented. The results of complex simulations that compare the quality of estimation of analyzed non-linear filters for complex non-linearities of state vector are presented. The moves of maneuvering object are described in two-dimensional Cartesian coordinates and the measurements are described in the polar coordinate system. The object dynamics is characterized by acceleration described by the univariate non-stationary growth model (UNGM) function. The filtering accuracy was evaluated not only by the root-mean-square errors (RMSE) but also by statistical testing of innovations through the expected value test, the whiteness test and the WSSR (weighted sum squared residual) test as well. The comparison of filtering quality was done in the MATLAB environment. The presented results provide a basis for designing more accurate algorithms for object location estimation.
\end{abstract}

\section{Keywords:}

non-linear filtering, extended Kalman filter, unscented Kalman filter, particle filter.

\section{INTRODUCTION}

Filtering algorithms used for navigation systems of positioning are based on the nonlinear equation of state as well as the measurement equation. They operate in a discrete time. Kalman filter allows to estimate error or state of an object in the $k^{\text {th }}$ step on the basis of measurements in the $k-1^{\text {th }}$ step. Kalman filters use information about dynamics of the object (system). Knowledge about system dynamics and its 
correct modeling is the main issue in Kalman filter implementation [Kaniewski, 2010]. In systems with nonlinear dynamics the object dynamics equations and/or observation equations are linearized using the extended Kalman filter (EKF). Linearization is carried out by means of partial derivatives of nonlinear state functions or their Taylor series expansion [Lampinen, 2004], [Konatowski, 2007]. The alternative to the EKF is unscented Kalman filter (UKF). This filter is a recursive estimating filter and its properties meet requirements of strongly nonlinear systems pretty well [Van der Merwe, 2001], [Arulampalam, 2004]. UKF operates on the statistical parameters of these models subjected to the non-linear transformations [Doucet, 2000]. UKF is based on unscented transform (UT), which converts the state vector into a set of weighted sigma points. These points are than used in algorithms for UKF. The UKF algorithm is a set of equations which are necessary to do prediction, innovation and correction steps. Another solution for the general filtering problem is based on the particle filter (PF) which uses the sequential importance sampling where the samples (particles) and their weights are drawn from the probability density [Gordon, 1993], [Doucet, 2001].

\section{EXTENDED KALMAN FILTER}

Assuming, that measurement and process noises are additive, the basic model for EKF filtering can be written as [Julier, 1997], [Lampinen, 2004], [Kaniewski, 2010]:

$$
\begin{gathered}
\mathbf{x}_{k+1}=\mathbf{f}\left(\mathbf{x}_{k}\right)+\mathbf{w}_{k} ; \\
\mathbf{y}_{k+1}=\mathbf{h}\left(\mathbf{x}_{k+1}\right)+\mathbf{v}_{k+1},
\end{gathered}
$$

where:

$\mathbf{x}_{k+1} \in R^{n} \quad$ - the state vector,

$\mathbf{y}_{k+1} \in R^{m} \quad$ - the measurement vector,

$\mathbf{w}_{k} \sim N\left(\mathbf{0}, \mathbf{Q}_{k}\right) \quad$ - the Gaussian noise of the process,

$\mathbf{v}_{k+1} \sim N\left(\mathbf{0}, \mathbf{R}_{k+1}\right)$ - the Gaussian noise of the measurement,

$\mathbf{f}(\cdot) \quad$ - the dynamics model function,

$\mathbf{h}(\cdot) \quad$ - the measurement model function.

The idea of the extended Kalman filter, which algorithm was shown in Figure 1, is based on the linearization of nonlinear dynamics and measurement 
functions [Lampinen, 2004], [Sosnowski, 2012]. This is realized, for example, via Taylor series expansion of the state $\mathbf{x}_{k+1}$ around the estimate $\hat{\mathbf{x}}_{k+1 \mid k}$ :

$$
\begin{aligned}
& \mathbf{f}\left(\mathbf{x}_{k+1}\right)=\mathbf{f}\left(\hat{\mathbf{x}}_{k+1 \mid k}\right)+\left.\frac{\partial \mathbf{f}\left(\mathbf{x}_{k+1}\right)}{\partial \mathbf{x}_{k+1}}\right|_{\mathbf{x}_{k+1}=\hat{\mathbf{x}}_{k+1 \mid k}}\left(\mathbf{x}_{k+1}-\hat{\mathbf{x}}_{k+1 \mid k}\right)+\ldots ; \\
& \mathbf{h}\left(\mathbf{x}_{k+1}\right)=\mathbf{h}\left(\hat{\mathbf{x}}_{k+1 \mid k}\right)+\left.\frac{\partial \mathbf{h}\left(\mathbf{x}_{k+1}\right)}{\partial \mathbf{x}_{k+1}}\right|_{\mathbf{x}_{k+1}=\hat{\mathbf{x}}_{k+1 \mid k}}\left(\mathbf{x}_{k+1}-\hat{\mathbf{x}}_{k+1 \mid k}\right)+\ldots
\end{aligned}
$$

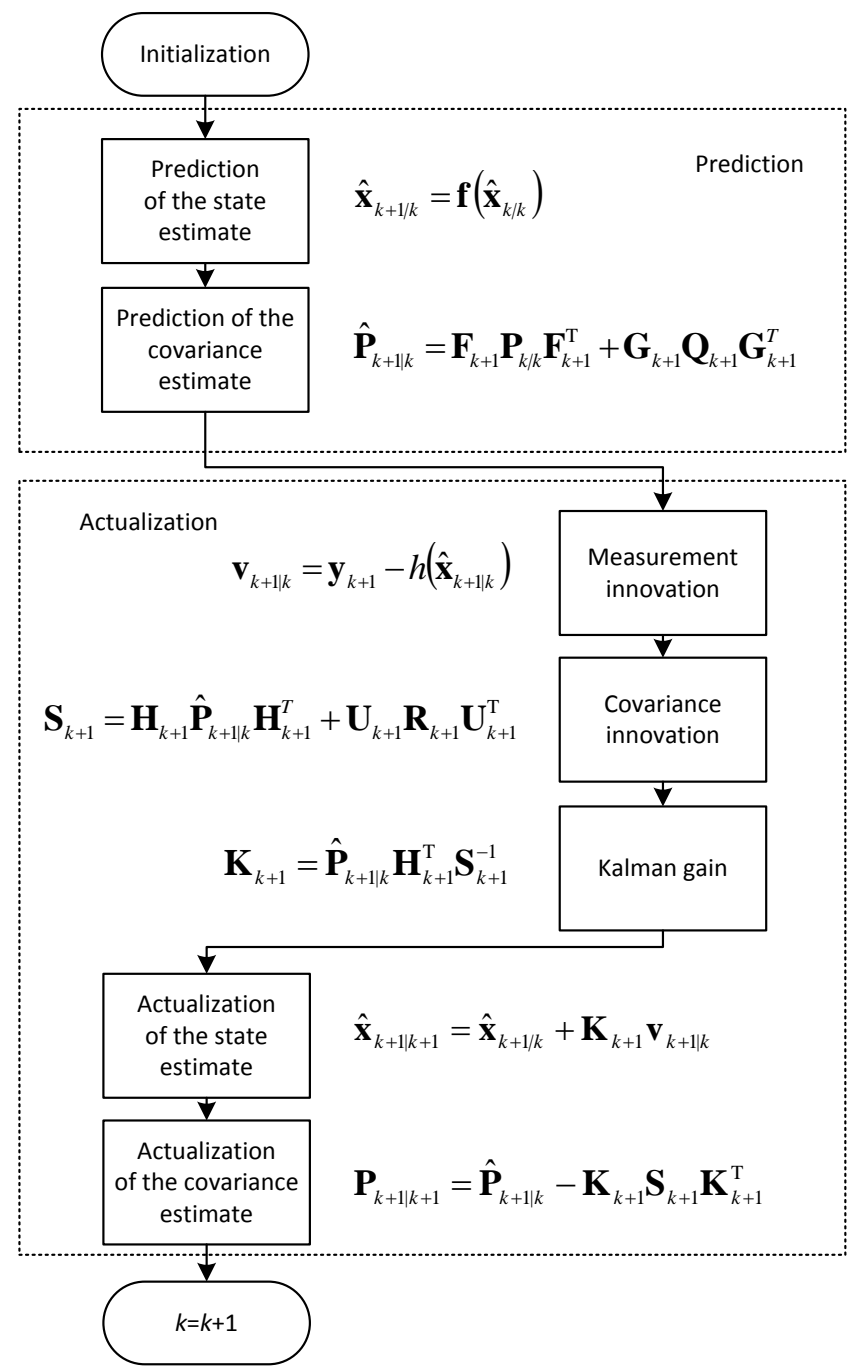

Fig. 1. Algorithm for extended Kalman filter 
Filtering with the extended Kalman filter of the first order (Taylor series expansion) consists of initialization, prediction, and actualization processes [Konatowski, 2009], (Fig. 1),

where:

$\mathbf{F}_{k} \quad$ - the matrix of the dynamics model at the time $t_{k}$,

$\mathbf{H}_{k+1}$ - the matrix of the measurement model at the time $t_{k+1}$,

$\hat{\mathbf{x}}_{k+1 \mid k+1}$ - the state estimate at the time $t_{k+1}$, based on measurements $\left\{\mathbf{y}_{1}, \ldots, \mathbf{y}_{k+1}\right\}$,

$\hat{\mathbf{x}}_{k+1 \mid k}$ - the state estimate at the time $t_{k+1}$, based on measurements $\left\{\mathbf{y}_{1}, \ldots, \mathbf{y}_{k}\right\}$,

$\mathbf{P}_{k+1 \mid k+1}$ - the covariance matrix of the errors of the state estimate,

$\hat{\mathbf{P}}_{k+1 \| k}$ - the covariance matrix of the errors of the state process prediction at the time $t_{k+1}$,

$\mathbf{v}_{k+1 \mid k}$ - the error of the measurement prediction at the time $t_{k+1}$,

$\mathbf{K}_{k+1}$ - the Kalman gains matrix,

$\mathbf{S}_{k+1}$ - the assistant matrix,

$\mathbf{F}_{k+1}=\left.\frac{\partial \mathbf{f}\left(\mathbf{x}_{k+1}\right)}{\partial \mathbf{x}_{k+1}}\right|_{\mathbf{x}_{k+1}=\hat{\mathbf{x}}_{k+1 \mid k}}$ - the Jacobian of the state,

$\mathbf{G}_{k+1}=\left.\frac{\partial \mathbf{f}\left(\mathbf{w}_{k+1}\right)}{\partial \mathbf{w}_{k+1}}\right|_{\mathbf{w}_{k+1}=\hat{\mathbf{w}}} \quad$ the Jacobian of the state noise,

$\mathbf{H}_{k+1}=\left.\frac{\partial \mathbf{h}\left(\mathbf{x}_{k+1}\right)}{\partial \mathbf{x}_{k+1}}\right|_{\mathbf{x}_{k+1}=\hat{\mathbf{x}}_{k+1 \mid k}}$ - the Jacobian of the measurement,

$\mathbf{U}_{k+1}=\left.\frac{\partial \mathbf{h}\left(\mathbf{v}_{k+1}\right)}{\partial \mathbf{v}_{k+1}}\right|_{\mathbf{v}_{k+1}=\hat{\mathbf{v}}} \quad$ - the Jacobian of the measurement noise.

Extended Kalman filter is easy in use and computably efficient. One of its limitations is that it works well only with small nonlinearities (close to linearity) since it is based on local linear approximation. Another deficiency is disregard of probabilistic uncertainties arisen in linearization of equations of state. Thus, for highly nonlinear models the EKF is not the optimum estimator [Gordon, 1993]. Due to Jacobians, measurement model and dynamics model must be differentiable. Only additive and Gaussian process noises are allowed. These problems can be solved by the unscented Kalman filter. 


\section{UNSCENTED KALMAN FILTER}

Unscented Kalman filter, proposed by Julier and Uhlmann [Julier, 1997], is based on Unscented Transformation (UT) used for statistics computation (first two moments) of a random vector undergoing transformation by nonlinear function. Unscented transformation describes statistical properties of the vector being transformed with the use of a finite set of points, called sigma points. The set of sigma samples is chosen deterministically so that statistical moments of the first and second order of the original distribution are projected in a complete way. Next these points are transformed via nonlinear process to the new space where they describe statistics of the distribution being transformed. On the base of them output statistics are calculated. The entire process can be described in three stages:

- assignment of number and location of a set of sigma points and their weights, based on unique characteristics (moments) of original distribution;

- nonlinear transformation of each point for obtainment of a new set of the points;

- computation of output statistics on the base of the transformed sigma points.

The algorithm of the unscented Kalman filter is a direct enlargement of the unscented transformation and consists of initialization, prediction, and actualization processes [Lampinen, 2004], [Konatowski, 2004], [Sosnowski, 2012]. It is presented in Figure 2.

For Gaussian processes Van de Merwe [Van der Merwe, 2001] suggested scaling parameter values as follows: $\left[\begin{array}{lll}\alpha & \beta & \kappa\end{array}\right]=\left[\begin{array}{lll}1 & 2 & 0\end{array}\right]$. The major advantage of the unscented Kalman filter is that it is not based on the local approximation. The Jacobians are not calculated so the functions $f$ and $h$ do not have to be differentiable. The use of sigma points in the UKF algorithm makes the filter storing higher order moments then the expanded Kalman filter [Doucet, 2000]. Like the EKF, the unscented Kalman filter can be used only for models with Gaussian noises. For the estimation of the state with non-Gaussian noises particle filters are used which are based on the sequential Monte Carlo method [Konatowski, 2010]. 


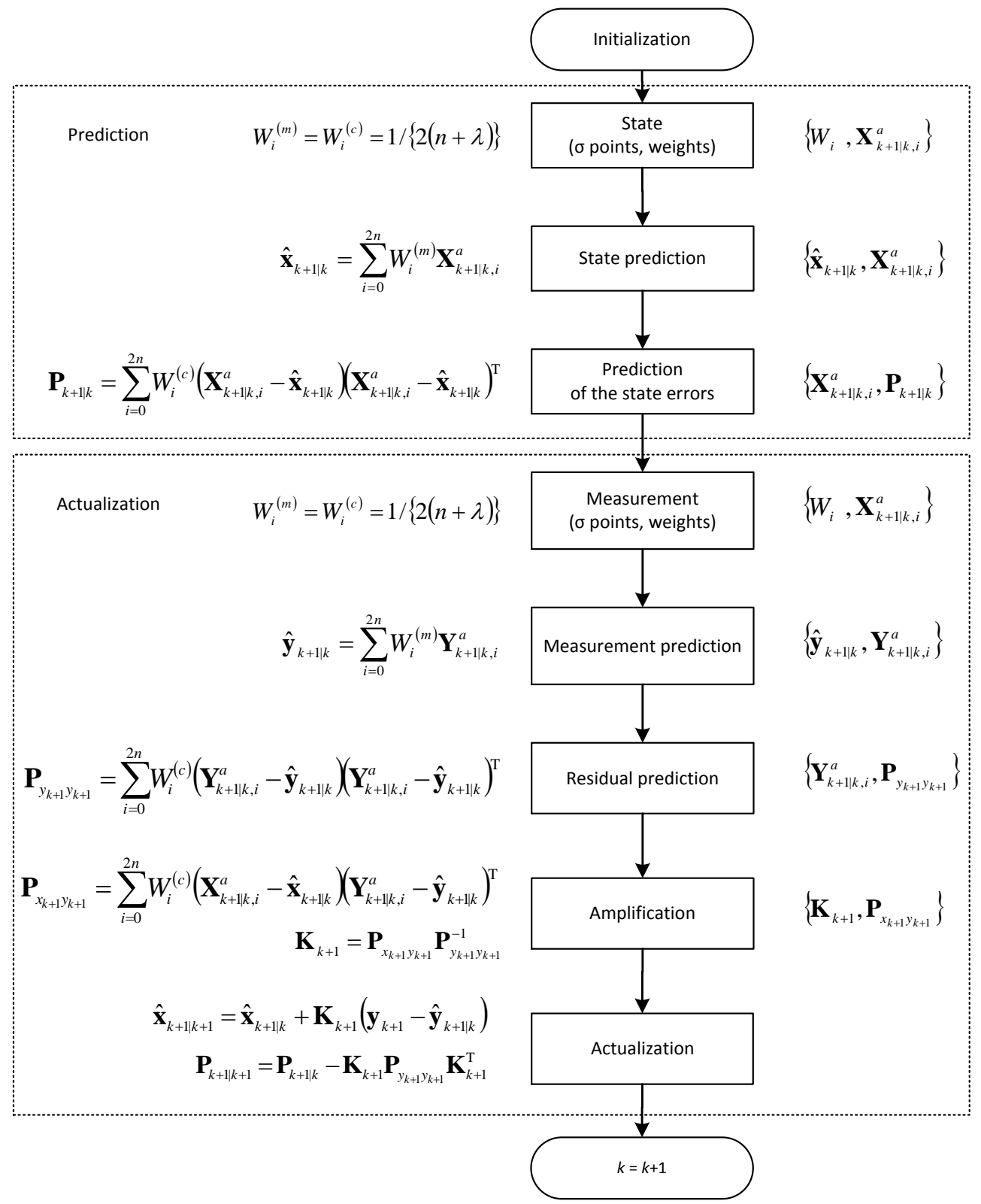

Fig. 2. Algorithm of the unscented Kalman filter

Where:

$\hat{\mathbf{x}}_{0}^{a}=\left[\begin{array}{lll}\overline{\mathbf{x}}_{0} & \mathbf{0} & \mathbf{0}\end{array}\right]^{\mathrm{T}} \quad$ - the initial expanded state vector, 
$\mathbf{P}_{0}^{a}=\operatorname{diag}\left[\begin{array}{lll}\mathbf{P}_{\mathbf{0}} & \mathbf{Q} & \mathbf{R}\end{array}\right] \quad$ - the initial expanded covariance matrix of the state, $W_{0}^{(m)}=\lambda /(n+\lambda) \quad$ - the initial weights of average values, $W_{0}^{(c)}=\lambda /(n+\lambda)+\left(1-\alpha^{2}+\beta\right)$ - the initial values of the covariance matrix, $n \quad$ - the dimension of the expanded state matrix,

$\lambda$ - the scaling parameter of the first order,

$\alpha \quad$ - the parameter for sigma points dispersion around the average value,

$\mathbf{x}_{k}^{a}=\left[\begin{array}{lll}\mathbf{x}_{k} & \mathbf{w}_{k} & \mathbf{v}_{k}\end{array}\right]^{\mathrm{T}}$ - the expanded state vector,

$\mathbf{X}_{k \mid k}^{a}=\left[\begin{array}{lll}\hat{\mathbf{x}}_{k \mid k}^{a} & \hat{\mathbf{x}}_{k \mid k}^{a}+\sqrt{(n+\lambda) \mathbf{P}_{k \mid k}^{a}} & \hat{\mathbf{x}}_{k \mid k}^{a}-\sqrt{(n+\lambda) \mathbf{P}_{k \mid k}^{a}}\end{array}\right]^{\mathrm{T}}$ - the sigma points set,

$\hat{\mathbf{x}}_{k \mid k}^{a} \quad$ - the expanded vector of the state estimate,

$\mathbf{P}_{k \mid k}^{a} \quad$ - the expanded covariance matrix of the state,

$\mathbf{X}_{k+1 \mid k, i}^{a}=\mathbf{f}\left(\mathbf{X}_{k \mid k, i}^{a}\right)$ - the sigma points propagated by the dynamics model,

$\mathbf{Y}_{k+1 \mid k, i}^{a}=\mathbf{h}\left(\mathbf{X}_{k+1 \mid k, i}^{a}\right)$ - the sigma points propagated by the measurement model,

$\hat{\mathbf{y}}_{k+1 \mid k}$ - the predicted value of the measurement,

$\mathbf{P}_{y_{k+1} y_{k+1}}$ - the predicted measurement covariance,

$\mathbf{P}_{x_{k+1} y_{k+1}}$ - the hybrid covariance matrix of the state and measurement.

\section{PARTICLE FILTER}

Particle filter uses Monte Carlo method - numerical method allowing calculation, for example, integrals impossible to solve in an analytical way [Arulampalam, 2004], [Cappe, 2005]. In this method, classical computations of statistical values are substituted by generation of samples on the base of random distribution and next on the base of estimation of distribution parameters from the average sample values.

In the ideal case, for sample number endeavoring to infinity, the expected value of a discrete variable reproduces a real expected value of a continuous variable with a certainty close to $100 \%$.

Frequently, due to high computational complexity, it is not possible to directly obtain samples from the probability density distribution of a variable $p(x)$. In this case an importance sampling technique is applied. This is based on the use of an approximate distribution (an importance distribution) from which sample can be generated in a simple way [Lampinen, 2004], [Konatowski, 2010]. 
Since the samples are generated from the importance distribution, a misrepresentation occurs which then can be overcome by attribution of adequate weights (weights) to individual samples.

The importance distribution $\pi(x)$ should allow easy sample generation and computation of their statistical parameters. Optimum, in terms of a variance, importance distribution should fulfill the condition

$$
\pi\left(x_{k+1} \mid x_{k}, y_{1: k+1}\right)=p\left(x_{k+1} \mid x_{k}, y_{1: k+1}\right) .
$$

Particle filtering uses sequential importance sampling SIS which is a recursive variant of the importance sampling. Its operation is based on the fact that one calculate can in each temporal step $k$ an importance distribution of the state $x_{k}$ and weight values in a recursive way. Algorithm SIS [Lampinen, 2004] uses a set of weighted particles $\left\{\left(w_{k+1}^{(i)}, x_{k+1}^{(i)}\right): i=1, \ldots, N\right\}$ in order to present filtering distribution $p\left(x_{k+1} \mid y_{1: k+1}\right)$. Disadvantage of this approach is that majority of weights equals zero, which happens very often. This is a so called degeneration problem which prevents practical implementation of particle filtering. An attempt to solve this problem is to re-sequential importance sampling SIR. In effect, particles with very low weights (low probabilities) are eliminated and those with high weights are duplicated.

The algorithm for re-sequential sampling is the following:

- calculation of new points $x_{k}^{(i)}$ on the base of importance distribution

$$
x_{k+1}^{(i)} \sim \pi\left(x_{k+1} \mid x_{k}^{(i)}, y_{1: k+1}\right)
$$

- calculation of new weight values

$$
w_{k+1}^{(i)}=w_{k}^{(i)} \frac{p\left(y_{k+1} \mid x_{k+1}^{(i)}\right) p\left(x_{k+1} \mid x_{k}^{(i)}\right)}{\pi\left(x_{k+1} \mid x_{0: k}^{(i)}, y_{1: k+1}\right)}
$$

and their normalization, so that the sum of all weights is equal zero

- check of the criterion and possible realization of a resampling with fixed step number or adaptive resampling.

Generally, resampling is executive when particle effective number is much less than their total number. Practically, this is accomplished when $n_{\text {effective }} \approx \sum_{i=1}^{N}\left(w_{k}^{(i)}\right)^{-2}$ is less than $10 \%$ of the total particle number, where $w_{k}^{(i)}$ 
are the normalized weights of $i^{\text {th }}$ particle in the temporal step $k$. The method of resampling greatly reduced the problem of degeneration [Doucet, 2001], [Konatowski, 2009]. The projection of better importance distributions will help to eliminate this problem.

Most often applied particle filter is a bootstrap filter (BS). It owes high popularity above all to its simplicity. This filter is a variant of SIR where the dynamics model $p\left(x_{k+1} \mid x_{k}\right)$ is used as an importance distribution. Because of low efficiency of the importance distribution, good results need a generation of a high number of Monte Carlo samples. The bootstrap filter is characterized by resampling executed in each temporal step [Sosnowski, 2012]. The algorithm of this filter (Fig. 3) is very similar to the SIR and can be presented in the following way:

- generation of a new set (using dynamics model) $\left\{x_{k}^{(i)}: i=1, \ldots, N\right\}$

$$
x_{k+1}^{(i)} \sim p\left(x_{k+1} \mid x_{k}^{(i)}\right)
$$

- calculation of weight values

$$
w_{k+1}^{(i)}=p\left(y_{k+1} \mid x_{k+1}^{(i)}\right)
$$

and their normalization so that the weight sum is equal 1

- execution of resampling:

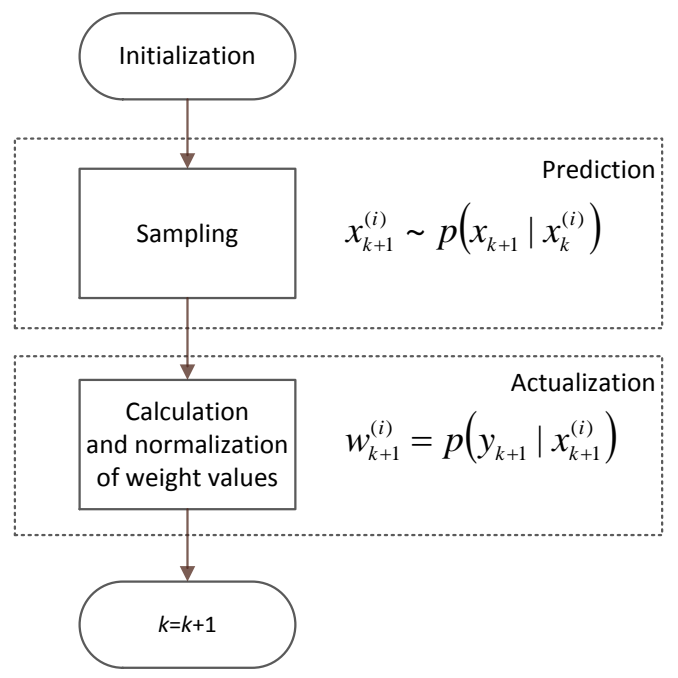

Fig. 3. Algorithm for bootstrap type particle filter 


\section{METHODS FOR ASSESSMENT OF ESTIMATION ACCURACY}

Most often determines the quality of the filtration mean square error [Kaniewski, 2010]. One of the methods for assessment of filtering accuracy is a statistical testing of the innovation process. The necessary and sufficient condition for the filter optimality is that innovation process, which is a difference between current values and expected values of the measurement vector, had normal distribution. A behavior of the innovation process can be assessed using the following statistical tests: expected value test, whiteness test, and the weighted-sum-squared-residual test (WSSR) [Sosnowski, 2012].

\section{The expected value test}

Assuming that the innovation vector $\mathbf{e}_{i}$ is ergodic and Gaussian [Julier, 1997], an average value of the sample $\hat{\mathbf{m}}_{e}$ can be used for estimation of an average value of the population $\mathbf{m}_{e}$. The estimator of the average value for the $i^{\text {th }}$ component of the innovation vector $\mathbf{e}_{i}$, expressed by the formula

$$
\hat{\mathbf{m}}_{e}(i)=N^{-1} \sum_{k=1}^{N} \mathbf{e}_{i}(k), \text { for } i=1, \ldots, N,
$$

where:

$i \quad$ - the component number of the innovation vector,

$N$ - the number of samples in the innovation vector,

$\hat{\mathbf{m}}_{e}(i)$ - the estimator of the average value for the $i^{\text {th }}$ component of the innovation vector,

$\mathbf{e}_{i}(k)$ - the $i^{\text {th }}$ innovation component for the temporal step $k$,

has normal distribution with the average value $\mathbf{m}_{e}$ and the variance equal $\mathbf{R}_{e e}(i) / N$.

The expected value test relies on a verification of the null hypothesis $\mathrm{H}_{0}: \mathbf{m}_{e}(i)=0$. The probability of the rejection of the $\mathrm{H}_{0}$ hypothesis for the threshold value $\tau_{i}$ with the significance level $\alpha$ is

$$
\mathbf{P}\left\{\left|\left[\hat{\mathbf{m}}_{e}(i)-\mathbf{m}_{e}(i)\right]\left[\mathbf{R}_{e e}(i) N^{-1}\right]^{-0,5}>\left[\tau_{i}-\mathbf{m}_{e}(i)\right]\left[\mathbf{R}_{e e}(i) N^{-1}\right]^{-0,5}\right|\right\}=\alpha
$$

It follows that the probability of acceptance or rejection of the $\mathrm{H}_{0}$ hypothesis trueness can be written as: acceptance of $\mathrm{H}_{0}$ for $\hat{\mathbf{m}}_{e}(i)<\tau_{i}$ or rejection of $\mathrm{H}_{0}$ for $\hat{\mathbf{m}}_{e}(i)>\tau_{i}$. For the null hypothesis $\mathrm{H}_{0}$ average value of the innovation 
vector is equal zero, therefore it is accepted that at the significance level $5 \%$ $(\alpha=0.05)$ the threshold value $\tau_{i}$ is

$$
\tau_{i}=1,96 \sqrt{\hat{\mathbf{R}}_{e e}(i) N^{-1}},
$$

where

$\hat{\mathbf{R}}_{e e}(i)$ is the variance of a set of a realization of the $i^{\text {th }}$ component of the ergodic innovation process, expressed by the formula

$$
\hat{\mathbf{R}}_{e e}(i)=N^{-1} \sum_{k=1}^{N} \mathbf{e}_{i}^{2}(k) .
$$

Rejection of the null hypothesis leeds to the acceptance of the alternative hypothesis $\mathrm{H}_{1}: \mathbf{m}_{e}(i) \neq 0$.

\section{The whiteness test}

The whiteness test verifies whether the covariance function for the ergodic innovation vector conforms to the covariance function of the uncorrelated white noise vector [Lampinen, 2004]. The covariance function of the $i^{\text {th }}$ covariance component, given by the dependence

$$
\hat{\mathbf{R}}_{e e}(i, \tau)=\frac{1}{N} \sum_{t=\tau+1}^{N}\left[\mathbf{e}_{i}(t)-\hat{\mathbf{m}}_{e}(i)\right] \cdot\left[\mathbf{e}_{i}(t+\tau)-\hat{\mathbf{m}}_{e}(i)\right],
$$

is used as the estimator, where $\tau$ is a delay of a correlation or a normalized covariance function

$$
\hat{\boldsymbol{\rho}}_{e}(i, k)=\hat{\mathbf{R}}_{e e}(i, k) \hat{\mathbf{R}}_{e e}^{-1}(i) \text {. }
$$

For high $N$ values this function takes form of the normal distribution with the expected value equal zero and the covariance equal $1 / N$. At 5\% significance level a threshold level can be obtained in the form of

$$
\tau_{i}=1,96 N^{-0,5} \text {. }
$$

Thus for high $N$ values even $95 \%$ of the estimator value of the normalized covariance function for the $i^{\text {th }}$ component is in the range

$$
\hat{\boldsymbol{\rho}}_{e}(i, k) \pm 1,96 N^{-0,5} \text {. }
$$


This test is useful for detection of inaccuracies of a model results applied for single components of the innovation vector, however for large observation vector size is very time-consuming.

\section{The WSSR test}

The WSSR test (weighted-sum-squared-residual) accumulates the entire information on the innovation vector in the window of the length $N$. The WSSR test is determined from the analysis of a value of the residual vector $\mathbf{e}_{k}$ and its covariance matrix $\mathbf{R}_{e}(k)$. This estimation is given by the formula

$$
\hat{\boldsymbol{\rho}}(l)=\sum_{k=l-N+1}^{l} \mathbf{e}^{T}{ }_{k} \mathbf{R}_{e}^{-1}(k) \mathbf{e}_{k} \text { for } l \geq N .
$$

It is based on verification of the null hypothesis $\mathrm{H}_{0}$, i.e. on comparison of a $\hat{\boldsymbol{\rho}}(l)$ value with the threshold value $\tau$ and taking one of the two decisions: acceptance of $\mathrm{H}_{0}$ when $\hat{\boldsymbol{\rho}}(l)<\tau$ or rejection of $\mathrm{H}_{0}$ when $\hat{\boldsymbol{\rho}}(l)>\tau$.

For the significance level $\alpha$, the probability of rejection is

$$
\left.\mathrm{P}\left\{\left|[\hat{\boldsymbol{\rho}}(l)-N p](2 N p)^{-0,5}\right|\right\rangle[\tau-N p](2 N p)^{-0,5}\right\}=\alpha,
$$

where

$N$ is the length of observation window and $p$ is the dimension of the observation vector. For $\alpha=0,05$ we get

$$
\tau=N p+1.96 \sqrt{2 N p} .
$$

It is accepted, that for $\hat{\boldsymbol{\rho}}(l)$ distribution assumed Gaussian the length of observation window fulfils the condition $N p>30$. With correct filter operation for at least $95 \%$ of the time, the $\hat{\boldsymbol{\rho}}(l)$ values should remain below the threshold value $\tau$.

\section{RESEARCH OF THE EKF, UKF AND PF FILTERS}

In simulation research the object movement was described in the two-dimensional Cartesian coordinate system while measurements in a polar coordinate system. Object dynamics is characterized by the state vector

$$
\mathbf{x}_{k+1}=\left[\begin{array}{llllll}
x_{k+1} & v_{k+1}^{x} & a_{k+1}^{x} & y_{k+1} & v_{k+1}^{y} & a_{k+1}^{y}
\end{array}\right]^{\mathrm{T}},
$$


where:

$x_{k+1}=x_{k}+T v_{k}^{x}+0,5 T^{2} a_{k}^{x}+w_{k}^{x}, y_{k+1}=y_{k}+T v_{k}^{y}+0,5 T^{2} a_{k}^{y}+w_{k}^{y}$ - the location coordinates,

$v_{k+1}^{x}=v_{k}^{x}+T a_{k}^{x}+w_{k}^{v^{x}}, \quad v_{k+1}^{y}=v_{k}^{y}+T a_{k}^{y}+w_{k}^{v^{y}} \quad$ - the velocity components,

$a_{k+1}^{x}=a_{k}^{x}+w_{k}^{a^{x}}, a_{k+1}^{y}=a_{k}^{y}+w_{k}^{a^{y}} \quad$ - the acceleration components,

$a_{k+1}^{x, y}=0.5 a_{k}^{x, y}\left[1+50\left(1+\left(a_{k}^{x, y}\right)^{2}\right)^{-1}\right]+8 \cos [1.2(k-1)]$ - the function of acceleration changes,

$w_{k}^{(\cdot)}$ - the adequate components of the vector of the state noise with a distribution $\mathbf{w} \sim \mathrm{N}(\mathbf{0}, \mathbf{Q})$,

$\mathbf{Q}=\operatorname{diag}\left\lfloor\begin{array}{llllll}\sigma_{x}^{2} & \sigma_{v^{x}}^{2} & \sigma_{a^{x}}^{2} & \sigma_{y}^{2} & \sigma_{v^{y}}^{2} & \sigma_{a^{y}}^{2}\end{array}\right.$,

$T$ - the discreteness period.

Observation model takes the general form

$$
\mathbf{y}_{\mathbf{k}}=\mathbf{h}\left(\mathbf{x}_{\mathbf{k}}\right)+\mathbf{v}_{\mathbf{k}} \text { for } \mathbf{v} \sim \mathrm{N}(\mathbf{0}, \mathbf{R}),
$$

where the nonlinear measurement function [Sosnowski, 2012] is

$$
\mathbf{h}\left(\mathbf{x}_{\mathbf{k}}\right)=\left[\begin{array}{lll}
\rho_{k} & \theta_{k} & \dot{\rho}_{k}
\end{array}\right]^{\mathrm{T}}=\left[\begin{array}{ll}
\sqrt{x_{k}^{2}+y_{k}^{2}} & \tan ^{-1}\left(\frac{x_{k}}{y_{k}}\right) \\
\frac{x_{k} v_{k}^{x}+y_{k} v_{k}^{y}}{\sqrt{x_{k}^{2}+y_{k}^{2}}}
\end{array}\right]^{\mathrm{T}},
$$

for measurement matrix $\mathbf{R}_{\mathbf{k}}=\operatorname{diag}\left[\begin{array}{lll}\sigma_{\rho}^{2} & \sigma_{\theta}^{2} & \sigma_{\dot{\rho}}^{2}\end{array}\right]$, in which the measuring values are: $\rho_{k}$ - distance, $\theta_{k}$ - azimuth angle and $\dot{\rho}_{k}$ - Doppler velocity.

In simulation tests the following initial conditions were taken: the $\mathbf{P}_{\mathbf{0}}$ unit matrix of uncertainties, the $\mathbf{Q}$ unit variance matrix of the state vector noises, while the initial values of the state vector and measurement errors matrix were found according to Ristic:

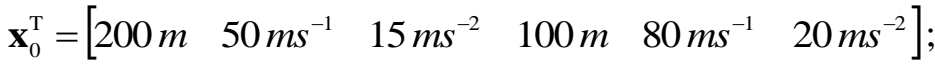

$$
\begin{aligned}
& \mathbf{R}=\operatorname{diag}\left[\begin{array}{lll}
625000 m^{2} & 1 \operatorname{deg}^{2} \quad 9 m^{2} s^{-2}
\end{array}\right] .
\end{aligned}
$$

In Figure 4 the results of the estimating the object location by three filters against actual route and the route measured are shown. It was assumed that object is located in the initial position $\mathrm{x}_{0}=200 \mathrm{~km}$ and $\mathrm{y}_{0}=100 \mathrm{~km}$. 


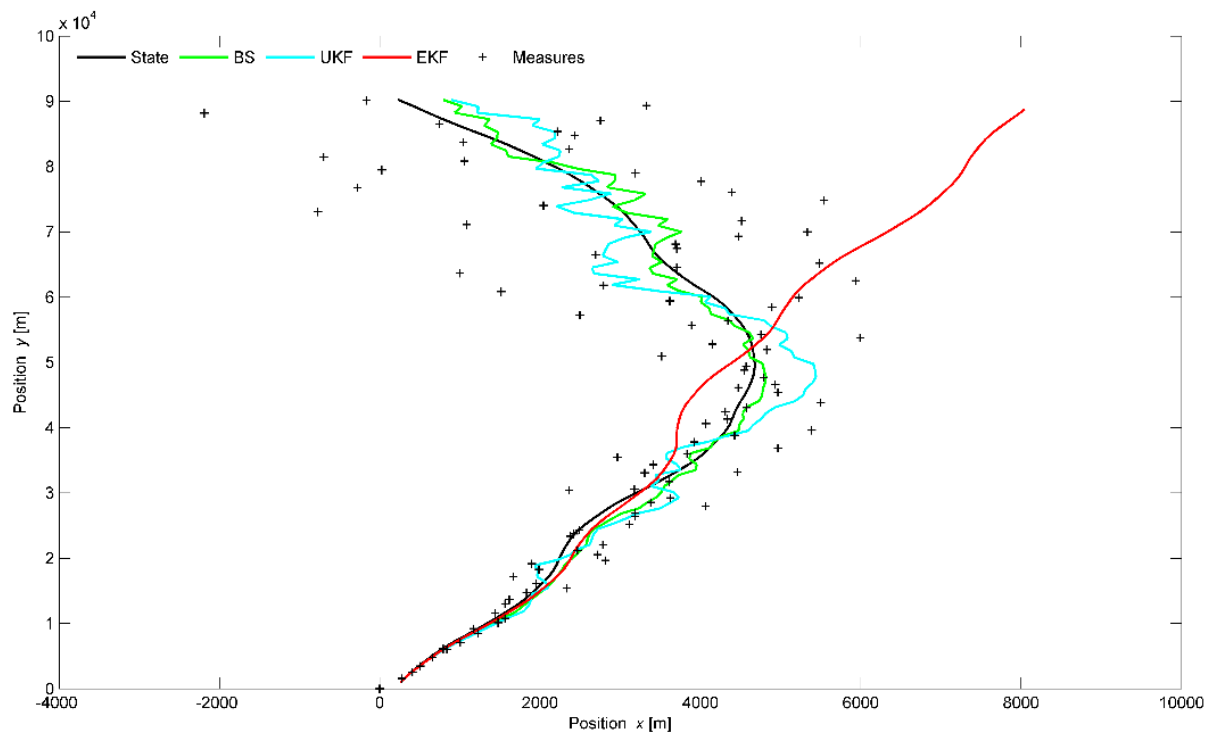

Fig. 4. Locations of an object estimated by the filters for the nonlinear measurement function

In Figure 5 errors of the estimation of the state vector elements, i.e. location components $x$, velocity components $v_{x}$, and acceleration components $a_{x}$ are illustrated.
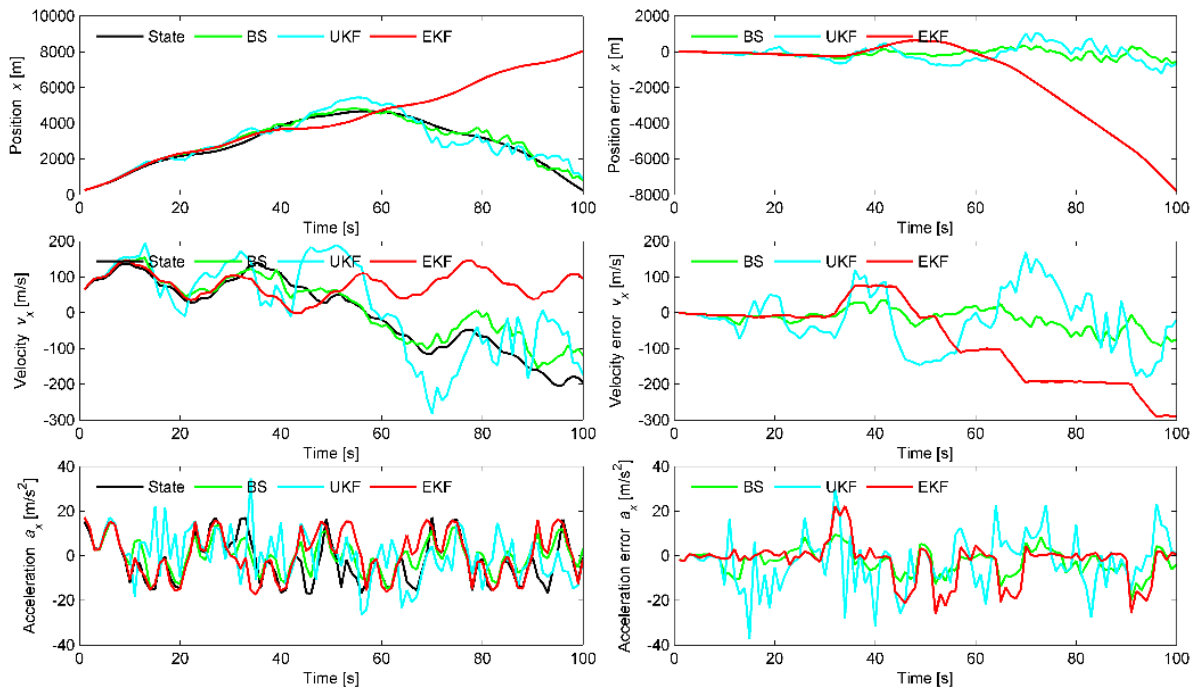

Fig. 5. Representation of location component $x$, velocity $v_{x}$, and acceleration $a_{x}$ with their errors 
In Figure 6 presented are the error values of the location component $x$ and the velocity component $v_{x}$ for three filters together with confidence intervals $\pm 1,96 \sigma$, in which should be $95 \%$ of the process values.
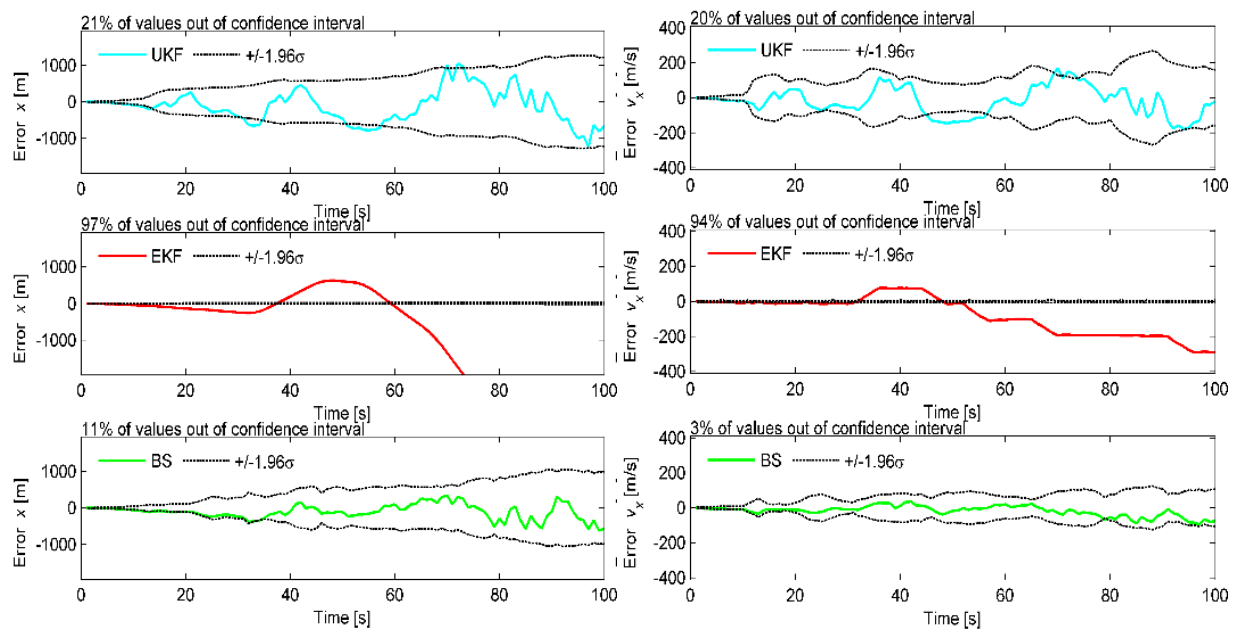

Fig. 6. Whiteness test results for location component $x$ and velocity error $v_{x}$ for the EKF, UKF, and BS filters

From the obtained error values for the object location and velocity estimation by analyzed filters, a clear advantage of the BS filter over the UKF and EKF filters is seen. In Table 1 the scale of values of the state vector elements found beyond the threshold values are shown.

Tab. 1. Combination of the filter estimation results

\begin{tabular}{|c|c|c|c|c|c|c|}
\hline \multirow{2}{*}{} & \multicolumn{6}{|c|}{ Percentage of values beyond the threshold values } \\
\cline { 2 - 7 } & $x$ & $y$ & $v_{x}$ & $v_{y}$ & $a_{x}$ & $a_{y}$ \\
\hline EKF & 97 & 97 & 94 & 99 & 31 & 32 \\
\hline UKF & 21 & 18 & 20 & 19 & 6 & 14 \\
\hline BS & 11 & 7 & 3 & 1 & 4 & 9 \\
\hline
\end{tabular}

Table 1 shows that all the components of the state vector are best estimated by BS filter. Estimation errors, determined for one set of input data of the filter $\mathbf{z}_{k}$, remain in their associated ranges $\pm 1,96 \sigma$ for about $89-99 \%$ of the time. Components of the measurement residual vector $\mathbf{e}_{k}$ of the UKF filter exceed the $\pm 1,96 \sigma$ range for $6-21 \%$ of the time. In turn, the estimation results of the EKF filter show a weak matching of the filtering algorithm to the estimated state $\mathbf{x}_{k}$. 
In Figure 7 and Table 2 cumulative results of filter estimation for whiteness tests, i.e. realization conformity the individual components of the measurement residuals vector $\mathbf{e}_{k}$ with corresponding confidence intervals $\pm 1,96 \sigma$ are presented.

The WT (whiteness-test) results are confirmed by the WSSR test showing a conformity of a variance of the measurement residuals vector with theoretical values of the $\mathbf{R}_{\mathrm{e}}$ matrix variance.
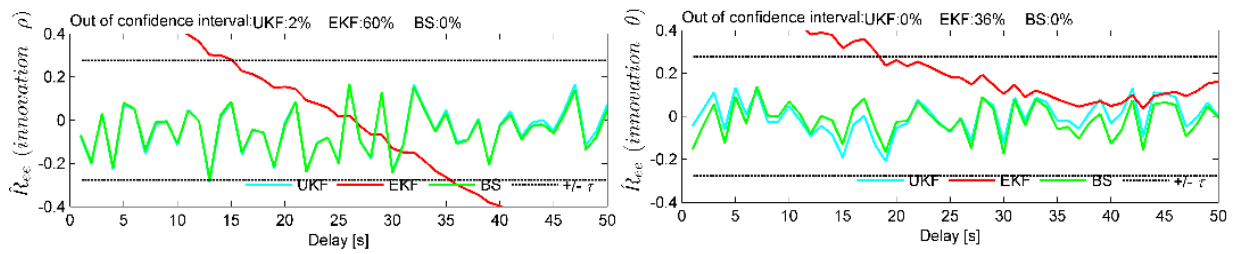

Fig. 7. Whiteness test results for the innovation vector

Table 2. The list of estimation results of filters for whiteness test and WSSR test

\begin{tabular}{|c|c|c|c|c|}
\hline \multirow{2}{*}{} & \multicolumn{3}{|c|}{ Percentage of values outside the confidence interval } \\
\cline { 2 - 4 } & \multicolumn{3}{|c|}{ Whiteness test } & \multirow{2}{*}{ WSSR } \\
\cline { 2 - 5 } & $\hat{\mathbf{R}}_{e e}$ (innov. $\rho$ ) & $\hat{\mathbf{R}}_{e e}$ (innov. $\left.\theta\right)$ & $\hat{\mathbf{R}}_{e e}$ (innov. $\left.\dot{\rho}\right)$ & \\
\hline EKF & 60 & 36 & 28 & 1 \\
\hline UKF & 2 & 0 & 6 & 2 \\
\hline BS & 0 & 0 & 4 & \\
\hline
\end{tabular}

In order to become independent of the noise influence on estimation accuracy, 200 filtering experiments were performed and average filtering errors were found (Fig.8).

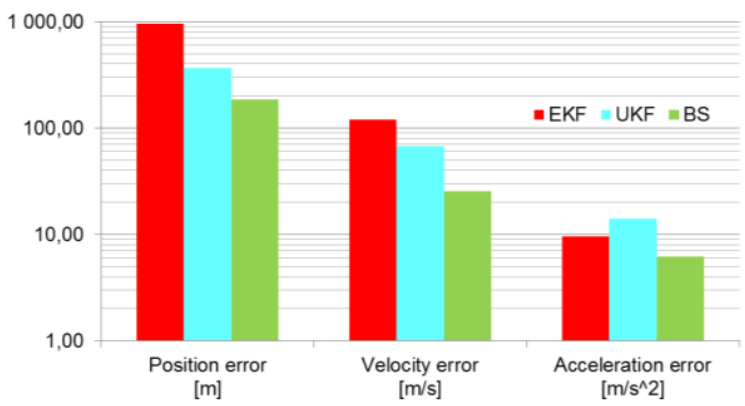

Fig. 8. Average errors of object movement parameters for the EKF, UKF, and BS filters 


\section{CONCLUSIONS}

Simulation tests included estimation of accuracy of location, velocity, and acceleration of an object in two-dimensional Cartesian coordinate system for three filters: expanded and unscented Kalman filters and a particle filter of the bootstrap type. Distance, azimuth, and Doppler velocity were found from measurement results of the object location. The object maneuverability is described by the UNGM function (univariate-non-stationary-growth-model).

The unscented Kalman filter does not need a local approximation, so in the process of its implementation the Jacobians are not computed and the nonlinear functions of state and measurement do not need to be differentiable. Compared with the expanded Kalman filter, this filter stores the second order moments, hence the accuracy of the state estimation is better. The EKF and UKF filters can be used only in dynamical models with Gaussian noise. For noises with other distributions particle filters must be applied [Konatowski, 2009].

Simulation tests determine filtering accuracy in the form of root-mean-square errors (RMSE) and characterize its efficiency via check what percentage of the obtained results, for the fixed significance interval, fulfils criteria for threshold values of the expected value test, the whiteness test, and the WSSR test.

Obtained results for estimation of location, velocity, and acceleration of a strongly maneuvering object, together with marked confidence intervals allow to find a usefulness of the individual filtering algorithms. When analyzing the results of estimation of the state vector elements by tested filters it can be seen that the lowest value of vector elements beyond the confidence interval is found for BS filter, compared to EKF and UKF filters. In practice, this means the best accuracy of this filter in the estimation process of coordinates of the tested object, its velocity and acceleration.

These observations were also confirmed by statistical tests of the innovation process carried out with use of: expected value test, whiteness test, and WSSR test. A list of percentage of estimation errors (location, velocity, and acceleration) placed outside assumed confidence intervals clearly indicate the usefulness of the tested algorithms. 


\section{REFERENCES}

[1] Arulampalam S., Gordon N., Ristic B., Beyond the Kalman Filter. Particie Fliters for tracking applications, Artech House, London 2004.

[2] Cappe O., Douc R., Moulines E., Comparison of resampling schemes for particle filtering, 4th International Symposium on Image and Signal Processing and Anlysis, 2005.

[3] Doucet A., de Freitas N., Van der Merwe R., Wan E. A., The unscented particle filter, Cambridge University Engineering Department, Cambridge 2000.

[4] Doucet A., Gordon N. J., Krishnamurthy V., Particle Filters for State Estimation of Jump Markov Linear Systems, 'IEEE Transactions on Signal Processing', 2001, Vol. 49, No. 3.

[5] Gordon N. J., Salmond N. J., Smith A. F. M., Novel approach to nonlinear/non-Gaussian Bayesian state estimation, 'IEE Proceedings-F', 1993, Vol. 140, No. 2, pp. 107-113.

[6] Julier S. J., Uhlmann J. K., A new extension of the Kalman filter to nonlinear systems, Proceedings of Aero Sense: The 11-th International Symposium on Aerospace/ Defense Sensing, Simulations and Controls, 1997.

[7] Kaniewski P., Structures, models and algorithms in integrated positioning and navigation systems, WAT, Warszawa 2010.

[8] Konatowski S., The development of nonlinear filtering algorithms, 'Przegląd Elektrotechniczny', 2010, Vol. 86, No. 9, pp. 272-277.

[9] Konatowski S., Kaczmarek B., Efficiency of the location estimation in nonlinear filtering algorithms, 'Przegląd Elektrotechniczny', 2009, Vol. 85, No. 3, pp. 15-21.

[10] Konatowski S., Pieniężny A., A comparison of estimation accuracy by the use of KF, EKF \& UKF filters, CMEM, WIT Press Southampton, Boston 2007, pp. 779-789.

[11] Konatowski S., Sipa T., Position estimation using Unscented Kalman Filter, 'Annual of Navigation', 2004, No. 8, pp. 97-110.

[12] Lampinen J., Särkkä S., Tamminen T., Vehtari A., Probabilistic Methods in Multiple Target Tracking, Laboratory of Computational Engineering Helsinki University of Technology, Helsinki 2004.

[13] Sosnowski B., Evaluation of estimation accuracy of nonlinear filters, WAT, Warszawa 2012.

[14] Van der Merwe R., Wan E. A., The square-root unscented Kalman filter for state and parameter-estimation, Proceedings of International Conference on Acoustics, Speech and Signal Processing, 2001.

Received September 2016

Reviewed December 2016 
STANISŁAW KONATOWSKI

Military University of Technology

Kaliskiego 2 Str., 201-476 Warsaw, Poland

e-mail: stanislaw.konatowski@wat.edu.pl

\section{PIOTR KANIEWSKI}

Military University of Technology

Kaliskiego 2 Str., 201-476 Warsaw, Poland

e-mail: piotr.kaniewski@wat.edu.pl

\section{JAN MATUSZEWSKI}

Military University of Technology

Kaliskiego 2 Str., 201-476 Warsaw, Poland

e-mail: jan.matuszewski@wat.edu.pl

\section{STRESZCZENIE}

W artykule opisane zostały algorytmy filtrów nieliniowych (rozszerzony EKF i bezśladowy UKF filtr Kalmana oraz filtr cząstkowy PF) stosowane powszechnie do estymacji położenia. Porównano dokładność estymacji tych filtrów dla nieliniowego równania pomiarowego. Zaprezentowane zostały rezultaty badań symulacyjnych porównujących jakość estymacji analizowanych rodzajów filtrów nieliniowych dla złożonej nieliniowości wektora stanu. Ruch obiektu manewrującego opisano w dwuwymiarowym układzie kartezjańskim, natomiast pomiary w polarnym układzie współrzędnych. Dynamikę obiektu charakteryzuje przyspieszenie opisane funkcją Univariate-Non-Stationary-Growth-Model.

Efektywność badań, poza określaniem błędów średniokwadratowych RMSE, oceniano poprzez statystyczne testowanie innowacji za pomocą: testu wartości oczekiwanej, testu białości oraz testu WSSR (Weighted-Sum-Squared-Residual). Ocena jakości procesu filtracji została przeprowadzona w środowisku MATLAB. Przedstawione wyniki stanowią podstawę do projektowania dokładniejszych algorytmów estymacji położenia obiektu. 